\title{
Commentary: Vitruvius lives on
}

\author{
Thomas G. Gleason, MD, MS
}

Louis Sullivan, the father of the skyscraper, first articulated the architectural modernist design credo that "form follows function" in 1896, ${ }^{1}$ deriving the concept from Vitruvius' original writings, De Architectura, of the first century BC. ${ }^{2}$ In medicine, Da Vinci is equally credited with an analogous dictum on his masterful L'uomo vitruviano (Vitruvian Man) and in his anatomic sketches published in the fifteenth century A.D. ${ }^{3,4}$ More recently, David and Yacoub and colleagues have embraced these concepts in their own studies and ultimate formulation of novel valve-sparing aortic root replacement (VSRR) techniques. ${ }^{5,6}$ In this month's Journal, Khachatryan and colleagues ${ }^{7}$ provide a succinct, well-written perspective piece on the use of David's reimplantation technique of VSRR for acute type A aortic dissection (ATAAD), detailing the Leipzig experience from 1995 to $2018 .^{7}$ Having translated his Toronto experience to Leipzig, Dr Borger and his team highlight their wealth of experience in using David's technique for ATAAD with outstanding short-term results.

The authors summarize the evolution of graft formulation and sizing strategies, ending with their tactic of determining the diameter of an "imaginary sinotubular junction" once the valve commissures have been lifted (suspended) to a point that allows for cusp coaptation-in other words, identifying a virtual sinotubular junction that optimizes commissural position, both their height and lateral excursion. Khachatryan and colleagues appropriately emphasize the need for "extensive mobilization" that allows for suspension of the commissures to an ideal height. Moreover, they allude to an understanding that the components of

From the Division of Cardiac Surgery, Brigham and Women's Hospital and Harvard Medical School, Boston, Mass.

Disclosures: Dr Gleason serves on a Medical Advisory Board for Abbott without significant remuneration.

The Journal policy requires editors and reviewers to disclose conflicts of interest and to decline handling or reviewing manuscripts for which they may have a conflict of interest. The editors and reviewers of this article have no conflicts of interest

Received for publication March 6, 2021; revisions received March 6, 2021; accepted for publication March 8, 2021; available ahead of print March 16, 2021.

Address for reprints: Thomas G. Gleason, MD, MS, Division of Cardiac Surgery, Brigham \& Women's Hospital, 75 Francis St, Boston, MA, 02115 (E-mail: tgleason@bwh.harvard.edu).

J Thorac Cardiovasc Surg 2022;164:820-1

0022-5223/\$36.00

Copyright (c) 2021 by The American Association for Thoracic Surgery

https://doi.org/10.1016/j.jtcvs.2021.03.028

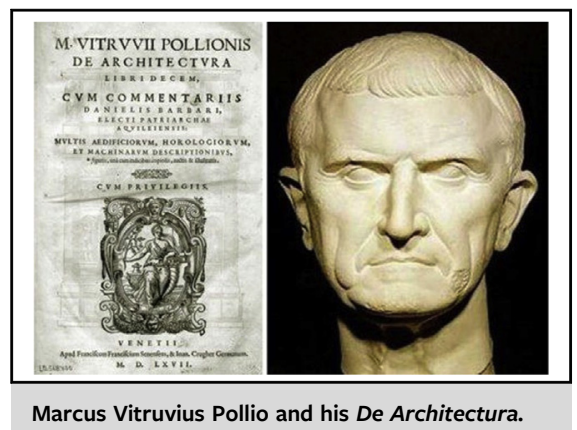

CENTRAL MESSAGE

Valve-sparing root replacement

is a viable alternative for manag-

ing type A aortic dissection, and cusp height is its fulcrum. Refinements in technique and graft composition are still necessary.

pathologic (eg, aneurysmal) roots may lose their normal geometric relationships, thus rendering reliance on their measurements (eg, annular dimension) for graft sizing inaccurate (or "misleading"). Although this certainly may be true for the annulus, sinuses, sinotubular junction, and even cusp leading edge length, all of which can be radically altered in the context of aneurysmal disease, annuloaortic ectasia, or aortic dissection, cusp height remains the one dimension that is typically preserved relative to its prior "normal" state and from which the remainder of the root should be refashioned to accommodate.

Hence, cusp height, or "depth" as measured from the cusp nodulus to the nadir of the cusp's basilar attachment, is a reliable measurement from which the rest of a root can be reconstructed, regardless of the presence or absence of root pathology. It is the one consistency that transcends root anatomy and root disease that can be relied on to guide VSRR. Notably, unlike cusp leading edge length, commissural position, annular dimension, sinotubular junction dimension, and sinus segment dimension, it is the one dimension that is not altered by repair maneuvers such as central plication, leading edge reinforcement, commissural plication, etc.

From here, debate persists as to the extent to which sinuses should be tailored (or prefabricated). Unquestionably, the amassed data on the topic to date, albeit inadequate with respect to volume and long-term follow-up, suggest that many graft formulations can yield a functioning valve and work. Although complacency in this regard may be 
attractive, given the worldwide results of the many described techniques, continuing to pursue the ideal-ie, nature: that which we see in a normal, unperturbed human root-valve complex-seems both prudent and requisite if we are to further advance the field. For example, the holy grail that still eludes us is a graft composition, sinus creation, and annular reconstruction strategy that preserves both aortic and annular compliance so that both the dynamism of the $\operatorname{root}^{8}$ and the Windkessel effect can be preserved in perpetuity and both stress and strain on the cusps can be minimized for durability.

Khachatryan and colleagues conclude that David's operation should be considered the procedure of choice for ATAAD in younger, lower-risk patients in experienced hands - predicated on an associated decreased risk of prosthetic valve-related complications. However, their own data lack long-term follow-up directed toward valve-related complication or reoperation rates. Alternatively, in a large cohort of 558 ATAAD patients in whom a more conservative approach of neomedial root repair and valve resuspension (that may better preserve at least root dynamism) was used, Bojko and colleagues ${ }^{9}$ demonstrated equivalent operative mortality statistics and very low 5-and 10-year rates of proximal aortic/valve reoperation $(0 \%-4.6 \%$, stratified by degree of aortic regurgitation at the time of ATAAD repair). At this point, there are no head-to-head comparisons of
VSRR to root repair and valve resuspension for ATAAD, and thus in planning operations for ATAAD, the consequences, both intended and unintended, as well as the surgeon's own experience, should be carefully considered. The ethereal truth that resurfaces in this latest contribution on the topic of ATAAD management is that form follows function.

\section{References}

1. Sullivan LH. The tall office building artistically considered. Lippincott's Mag. 1896;403-9.

2. Vitruvius P. The Ten Books on Architecture. Cambridge, Mass: Harvard University Press; 1914.

3. Da Vinci L. Anatomical Drawings From the Royal Collection. London: The Royal Academy of Arts; 1977.

4. Da Vinci L. L'uomo vitruviano. Gallerie dell'Accademia, Venice, Italy; 1490.

5. David TE, Feindel CM. An aortic valve-sparing operation for patients with aortic incompetence and aneurysm of the ascending aorta. $J$ Thorac Cardiovasc Surg. 1992;103:617-21; discussion 622.

6. Yacoub MH, Fagan A, Stassano P, Radley-Smith R. Results of valve conserving operations for aortic regurgitation. Circulation. 1983;68:311-21.

7. Khachatryan Z, Herajärvi J, Leontyev S, Borger M. Valve-sparing aortic root replacement can be done safely and effectively in acute type A aortic dissection. J Thorac Cardiovasc Surg. 2022;164:814-9.

8. Yacoub MH, Kilner PJ, Birks EJ, Misfeld M. The aortic outflow and root a tale of dynamism and crosstalk. Ann Thorac Surg. 1999;68(3 Suppl): S37-43.

9. Bojko MM, Habertheuer A, Bavaria JE, Suhail M, Hu RW, Harmon J, et al. Recurrent aortic insufficiency after emergency surgery for acute type A aortic dissection with aortic root preservation. J Thorac Cardiovasc Surg. April 18, 2020 [Epub ahead of print]. 